\title{
Dutch nursing students' knowledge and attitudes towards older people - A longitudinal cohort study
}

\author{
Nienke Bleijenberg', Michel. J. M. Jansen ${ }^{2}$, Marieke J. Schuurmans ${ }^{3}$ \\ 1. Julius Center for Health Science and Primary Care, University Medical Center Utrecht, the Netherlands. 2. Faculty of \\ Health Care, University of Applied Sciences, the Netherlands. 3. Department of Rehabilitation, Nursing Science and Sports, \\ University Medical Center Utrecht, the Netherlands
}

Correspondence: Nienke Bleijenberg. Address: Julius Center for Health Science and Primary Care, University Medical Center Utrecht Postbus 85500, The Netherlands. Telephone: 31-887-553-612. Email: N.Bleijenberg@umcutrecht.nl

Received: November 11, 2011 Accepted: December 13, 2011 Published: May 1, 2012

DOI : 10.5430/jnep.v2n2p1

URL: http://dx.doi.org/10.5430/jnep.v2n2p1

\section{Abstract}

Background: Due to changing demographics in the population, the majority of current nursing students will work mostly with older people after graduation. It is known that most nursing students have little knowledge and interests in working with older people. There is a growing need for motivated nurses to provide care for older people as the quality of care is influenced by their attitudes. The objective of this study is to investigate Dutch nursing students' knowledge of and attitudes toward older people and their willingness to work with older people and how this knowledge and attitudes changes after three years education.

Methods: A longitudinal cohort study with follow-up among 113 first-year Dutch nursing students pursuing a Bachelor's degree was conducted. Data for this study was collected with three instruments. Knowledge of the first-year students was assessed with Palmore's Facts on Aging Quiz. Students' attitudes were measured with the Aging Semantic Differential scale and Kogan's Attitudes toward Older People scale. The same measurements were also obtained three years later when they were fourth-year nursing students. The first data collection started in 2005. The follow-up period took place between 2008 and 2009.

Results: The results show that the nursing students have a moderate knowledge level about older people: first-year students answered less than half of the questions correctly and after three years, almost half of the questions were answered properly. The attitude of the students toward older people on the ASD changed from slightly negative to neutral after three years of education. The attitude of nursing students on the OP changed from moderately neutral to slightly positive. Few first and fourth-year students (2.7\% and 3.7\%) were interested in working with older people after their nursing education. Most students (72.8\%) indicated that working with older people would be as satisfying as working with younger people.

Conclusion: Nursing students are not well prepared for working with predominately older people. Education should focus on increasing positive working experiences with older people. Revision and improvement in the curricula might be needed to enhance the knowledge and attitudes of the Dutch nursing students.

\section{Key words}

Attitudes, Knowledge, Nursing students, Older people 


\section{Introduction}

Current demographic changes and an aging population across the world demand an increase in the care of older people. In 2030, approximately $28 \%$ of Western Europe's population and $21 \%$ of the US population will be 65 years or older ${ }^{[1]}$. This expected growth in the number of people aged 65 years and older will cause the number of people with chronic diseases and multimorbidity to rise. Canadian researchers recently calculated that within the next 20 years, $75 \%$ of all available nursing care will be given to persons aged 65 years and older ${ }^{[2]}$. In the Netherlands, today, more than half of all hospital beds are occupied by people of 65 years or older ${ }^{[3]}$.

Given these aging changes in the population, it is clear that nearly all nursing students will predominately work with older people after graduation, regardless of whether they choose to do so. Therefore, there is a growing need for motivated nurses to provide care for older people. It is essential that nursing students are adequately prepared for taking care of this growing population because nurses have a pivotal role as providers of care and are in a unique position to influence the quality of care ${ }^{[4]}$.

In the last decade, several studies investigating nursing students' knowledge of, and attitudes toward older people and their willingness to work with them have been conducted in Jordan, Australia, Greece, Belgium, Turkey and China ${ }^{[4-10]}$. The majority of these studies concluded that most nursing students have little knowledge and interest in working with older people ${ }^{[4,8,10,11]}$. Furthermore, it is known that the quality of care is influenced by the ageism and attitudes of healthcare workers towards older people ${ }^{[12-14]}$. This attitude may be affected by personal experiences with older people or either the role of education can have a positive or negative influence on nurses' attitudes ${ }^{[5,15,16]}$. Azjen and Fishbein's "Theory of Reasoned Action" suggests that attitudes can influence an individual's behavior and that people with a positive attitude towards anyone will have more positive thoughts about them ${ }^{[17]}$. Therefore, measuring and improving nursing students' attitudes toward aging is essential to increase the number of nursing students who desire to work with this population. Education can play an important role in the development of a positive attitude toward older people when teachers are aware of their function as role model ${ }^{[13,14]}$. Previous studies found that students who had more experiences and interaction with older people also had more positive attitudes and a higher level of knowledge ${ }^{[6,15,18]}$.

Little is known to date about the knowledge and attitude of Dutch nursing students toward older people or how this develops during their four-year bachelor education program. To determine potential problems that can threaten the future quality of care for older people it is important to understand what the attitude of nursing students' toward older people is.

Therefore, the aim of this study is to investigate the knowledge and attitudes of Dutch nursing students and how this knowledge and attitude changes during their education. Specific questions regarding the students' willingness to work with older people and the relationship between nursing students' knowledge of and attitudes toward older people will be answered within this study.

\section{Methods}

\subsection{Design}

A longitudinal cohort study with follow-up among nursing students was conducted.

\subsection{Setting and participants}

Bachelor of nursing students of the Hogeschool Utrecht (HU), University of Applied Sciences were recruited in their first year of education to participate voluntarily in this study during regular education lessons. Permission was received from the responsible course managers of the HU. Questionnaires were distributed and collected during allocated class time. The completion and return of the anonymous questionnaires were perceived as consent giving to participate in the study. The 
first data collection was conducted between November 2005 and May 2006 during the students' first year. The follow-up was conducted between December 2008 and February 2009, when the students were in their fourth year. Given the fact that not all students participated, that students dropped out of their educational program or delayed their education, the cohort of first-years students is not equal to the follow up cohort. Although not all students participated, it is not likely that the students who did not participate are significantly different than patients who did participate in the study. No additional data was collected on those students who left the study.

\subsection{Bachelor of nursing in the Netherlands}

In the Netherlands, a Bachelor of Nursing degree is a four-year educational program. Each year consists of four blocks of ten weeks. First-year students received three blocks of theory classes and one block is an internship in clinical practice. Both theory classes and internship are obligatory. The content of the three theory blocks includes courses on older patients, psychiatric patients, patients with mental disorders and patients with highly intensive clinical care. The second year of the education program consisted of theory classes about chronic care and care for younger adults and an internship of ten weeks. During the third and fourth-year students had twenty weeks of various theory blocks and twenty weeks an internship in different health care fields e.g. hospital, community, psychiatry or nursing or elderly homes. During the total educational program, the amount of specific geriatric education was fourteen hours, including lectures, self study and problem-based learning where students had to solve patient case descriptions. The first-year students that participated in this study had already completed their ten-week internship. Most students had their first internship in a nursing home or elderly home. Fourth-year nursing students had completed 40 weeks of various internships when they participated in this study.

\subsection{I nstruments}

The Facts on Aging Quiz (FAQ) from Palmore and colleagues was used to measure the knowledge of the nursing students about older people ${ }^{[19]}$. The attitude of nursing students was measured with two questionnaires: the Aging Semantic Differential (ASD) developed by Rosencranz and McNevin ${ }^{[20]}$ and the Attitudes toward Old People (OP) developed by Kogan ${ }^{[21]}$. Translated questionnaires were used as described in a study in Flemish nursing students' attitude towards older people $^{[8]}$.

\subsection{Facts on Aging Quiz (FAQ)}

The FAQ consists of 25 statements about physical, psychological and social facts concerning aging and older people that can be answered with 'true', 'false' or 'don't know. Questions answered correctly were scored as 1 point. All incorrect answers and questions answered with 'don't know' were scored as 0 points. The maximum score is 25, and a higher score indicates more knowledge about older people. The FAQ ‘true-false version’ was first developed in 1977 by Palmore ${ }^{[19]}$. In 1998, Palmore recommended modifying this format and included a 'don't know' option. The internal consistencies of both versions were compared. A Cronbach's alpha of $\alpha=0.40$ was found on the original 'true-false' version, and an alpha of $\alpha$ $=0.83$ was found with the added 'don't know' option ${ }^{[22]}$. The translated FAQ version had a limited reliability, with a Cronbach's alpha of $0.59^{[8]}$.

\subsection{Aging Semantic Differential (ASD)}

The ASD consists of 32 adjectives concerning attitudes towards older people. Based on a 7-point scale, nursing students had to indicate which characteristics most accurately fit older people. The score ranges from 32 (highly positive attitude) to 224 (highly negative attitude). A score of 128 is considered to be neutral. The validity of the scale was not described in the original study of Rozencranz and McNevin (1969) ${ }^{[20]}$. The internal consistency was tested by Beullens \& Martens (2000) and was found to be sufficient (Cronbach's alpha: $0.87{ }^{[8]}$.

\subsection{Attitudes toward Old People (OP)}

The OP consists of 34 statements about older persons: 17 negative and 17 positive statements are measured on a 7-point scale. Responses range from 1 (strongly disagree) to 7 (completely agree). Responses to the positive items are converted to 
a negative score so that a higher score indicates a more negative attitude. The minimum score is 34 , the maximum score is 238, and the neutral middle score is 136. Kogan (1961) ${ }^{[21]}$ found a Cronbach's alpha of 0.66 to 0.83 for individual subscales. The Cronbach's alpha from the translated version was 0.74 respectively ${ }^{[8]}$.

Additional information known from the literature to potentially influence attitudes toward older people, such as age, gender and internship experience with older adults, were collected ${ }^{[8,16,23]}$. In addition, students were asked about the number of their grandparents still living, whether they have family or friends with dementia, and if they expect to be as satisfied with working with older people as with younger people. Finally, students were asked in which health sector they preferred to work after graduation: pediatrics, psychiatry, community care, hospital or a nursing home, and whether they would like to work with people aged 65 years or older.

\section{Analysis}

The data analysis was performed with the Statistical Package for the Social Sciences (SPSS) version 16.0. The total sum of scores from the first- and fourth-year nursing students on the FAQ, ASD and OP were compared. An independent sample $t$-test was used to determine whether the knowledge about and attitudes toward older people of nursing students changed between their first and fourth year. Furthermore, the Pearson's correlation coefficient was used to test the relationship between students' knowledge about and attitudes toward older people (correlation between ASD and OP with FAQ). A difference was deemed statistically significant for $p$-values less than 0.05 .

\section{Results}

Out of the 190 registered first-year nursing students, a total of 113 students (59.4\%) completed the questionnaire. After three years, the number registered number of nursing students decreased to 124. A total of 81 fourth-year students (65.3\%) completed the questionnaire. Characteristics of the first- and fourth-year students are presented in table 1.

Table 1. Characteristics of the Dutch first- and fourth-year nursing students. (p.7)

\begin{tabular}{lll}
\hline Characteristics & $\begin{array}{l}\text { First-years nursing students } \\
\text { (N = 113) }\end{array}$ & $\begin{array}{l}\text { Fourth-year nursing students } \\
\text { (N = 81) }\end{array}$ \\
\hline Women & $81.4 \%$ & $87.7 \%$ \\
Age, mean (SD) & $19.69(2.2)$ & $22(1.9)$ \\
Volunteer experience with older adults* & $16.6 \%$ & $23.5 \%$ \\
Living with older people* & $3.5 \%$ & $7.4 \%$ \\
Family with dementia* & $29.2 \%$ & $39.5 \%$ \\
Experience as caregiver * & $34.5 \%$ & $48.1 \%$ \\
Caregivers in family* & $44.2 \%$ & $42 \%$ \\
\hline
\end{tabular}

*\% answered with yes.

\subsection{Knowledge about older people}

The average score of first-year nursing students on the FAQ was 11.2 (SD: 2.8), which indicates that less than half of the questions were answered correctly. After three years, the average score was 12.6 (SD: 4.5) (see Table 2). This slightly higher mean score of the fourth-year students shows that they had little more knowledge about the elderly than when they were first-year students, and this difference was statistically significant $(p=0.02)$. Due to this small difference in knowledge we compared three groups of knowledge levels: low: 0-8; moderate: 9-17 and high: 18-25. Most students had a moderate knowledge level about older people (69.1\%); $17.3 \%$ of the students had a low knowledge level, and $13.6 \%$ of the 
fourth-year nursing students had a high knowledge level. By studying the items of the FAQ separately, insight was gained in the content of their knowledge. A majority of the fourth-year nursing students answered the items about happiness, loneliness, the number of older people living in a long-stay institution incorrectly: $43.2 \%$ of the students thought that a majority of older people are unhappy most of the time, 56.8\% thought that a majority of older people are socially isolated and $73 \%$ of the students thought that at least $10 \%$ of the elderly live in long-stay institutions, although the actual percentage in the Netherlands is around $3 \%{ }^{[24,25]}$. Finally, most students $(63 \%)$ thought that the majority of older people are often bored.

Table 2. Change in knowledge about and attitudes towards older people. (p.7)

\begin{tabular}{|c|c|c|c|}
\hline Item & $\begin{array}{l}\text { First-year nursing students } \\
(\mathrm{N}=113)\end{array}$ & $\begin{array}{l}\text { Fourth-year nursing students } \\
(\mathrm{N}=\mathbf{8 1})\end{array}$ & $P$-value \\
\hline Knowledge on FAQ, mean (SD) & $11.2(2.8)$ & $12.6(4.5)$ & 0.01 \\
\hline Attitude on ASD, mean (SD) & $132.7(18.4)$ & $128.6(16.06)$ & 0.11 \\
\hline Attitude on OP, mean (SD) & $130.6(9)$ & $127(11.06)$ & 0.02 \\
\hline
\end{tabular}

\subsection{Attitudes toward older people}

First-year nursing students had a neutral to slightly negative attitude toward older people measured with the ASD. A mean score of 132.7 (SD: 8.4) was found, which is 4.7 points above the neutral score of 128 (see Table 2). A lower score on the ASD indicates a more positive attitude. After four years the students had a neutral score on the ASD (mean: 128.6, SD: 16.1). Although the attitude changed from slightly negative to neutral, the difference between the first and fourth-year students was not statistically significant $(p=0.11)$.

Measured with the OP, the first-year students had a moderately neutral to slightly positive attitude toward older people. A mean score of 130.6 (SD: 9) was found which is almost six points below the neutral score of 136. After three years, a more positive attitude was found (mean: 127.0, SD: 11.1) and the differences after three years was statistically significant $(p=0.02)$.

\subsection{Correlation between attitude and knowledge}

Using the Pearson's correlation coefficient, we tested whether fourth-year nursing students with more knowledge about older people also think more positively about them. ASD scores showed a low negative correlation with FAQ scores (-0.3, $p=0.03$ ), indicating that students with more knowledge about older people are more likely to ascribe positive traits to them. The OP and FAQ and the ASD and OP were also lowly negatively correlated (-0.03, $p=0.8$ and $-0.05, p=0.7)$; however, these differences were not significant.

\subsection{Preferences and satisfaction in working with older people}

We asked nursing students if they preferred to work with older people after graduation. Only 2.7\% of the first-year nursing students answered this question positively, 68.1\% responded with 'certainly not' or 'prefer not'. The remaining $29.2 \%$ indicated that it made no difference whether they worked with people 65 years or older. After three years of education this percentage was still low: only 3.7\% preferred to work with older people. The majority of the fourth-year nursing students (54.3\%) preferred not to work with older people. The remaining 42\% (34 students) reported that for them it makes no difference. Most first- and four- year students (62.8\% and 72.8\%) would be as satisfied working with older people as with younger people. Finally, most first-year students (72\%) and more than half of the fourth-year students (56.8\%) preferred to work in a hospital after graduation (see Table 3). 
Table 3. Preferred health sector for working after graduation

\begin{tabular}{lll}
\hline Item & $\begin{array}{l}\text { First-year nursing students } \\
(\mathbf{N}=\mathbf{1 1 3})\end{array}$ & $\begin{array}{l}\text { Fourth-year nursing students } \\
\mathbf{( N = 8 1 )}\end{array}$ \\
\hline Hospital & $72 \%$ & $56.8 \%$ \\
Psychiatry & $16.8 \%$ & $23.5 \%$ \\
Community care & $6.5 \%$ & $6.2 \%$ \\
Pediatrics & $3.7 \%$ & $13.6 \%$ \\
Nursing home & $0.9 \%$ & $0 \%$ \\
\hline
\end{tabular}

\section{Discussion}

In this study, we investigated knowledge about and attitudes towards older people of a cohort of Dutch nursing students and how these aspects changed during their nursing education. Our findings indicate that students in their first-year and in their fourth-year nursing students have a moderate knowledge level about aging and older people. The attitude of the fourth-year students changed from slightly negative to neutral on the ASD and from moderately to slightly positive on the OP. A low negative correlation $(-0.25, p=0.03)$ was found between ASD and FAQ score, indicating that students with more knowledge about older people are more likely to ascribe positive traits to them which is in line with the theory of "Reasoned Action" from Azjen and Fisbein ${ }^{[17]}$. A majority of the first-year students (68.1\%) and 54.3\% of the fourth-year students preferred to not work with older people. However, a majority of the same students (72.8\%) indicated that working with older people would be as satisfying as working with younger people.

Several limitations of this study that could influence our results must be addressed. First, due to the small size of this study and because the participants were limited to Dutch nursing students at one educational institute, the results are difficult to generalize to other populations. Second, because a dynamic cohort of nursing students was used, it was not possible to analyze the data on an individual level. Third, the first-year students had already completed a ten week internship at the moment they participated in the study. This experience with taking care of older people may have influenced the students perception and knowledge of elderly. Therefore it is possible that a higher mean score on the instruments during the first data collection was found. Finally, although the FAQ and ASD scales are commonly used in scientific research to measure knowledge and attitude, some criticisms of the measurement scales exist. Harris and coworkers (1996) concluded that the internal consistency of the FAQ was insufficient ${ }^{[26]}$. Scoring opportunities are too limited according to the authors, and they pose too high of a risk too. Therefore, we used the FAQ with an added "don't know" option. Pennington and coworkers found that in a modified version of the FAQ, this additional option showed higher validity than the original 'true-false' design ${ }^{[22]}$. Other authors assumed that the language in the ASD could result in more negative scores because the term 'elderly' was used ${ }^{[27]}$.

One of the strengths of this study is the longitudinal design. A majority of other studies investigating knowledge about and attitudes toward older people have a cross-sectional design ${ }^{[4,28,29]}$. Because of this longitudinal design it was possible to evaluate the change in nursing students' knowledge, attitudes and interest in working with older people over time. To our knowledge, no study has been carried out yet on the knowledge and attitudes of Dutch nursing students toward older people with follow-up.

The moderate knowledge level of Dutch nursing students corresponds to other studies that measured the knowledge of students measured with the FAQ ${ }^{[6,12,15,28]}$. In this study nursing students' knowledge increased after three years of education, which is consistent with the results of other studies ${ }^{[6,12]}$. Although a small increase in knowledge was found, its clinical relevance is unclear. Fourth-year nursing students had poor knowledge about demographic numbers, loneliness and older peoples' social activities. In this study it is unknown if this is related with the amount of gerontological education during their nursing education. Further research is needed to investigate if an increase in the amount of gerontological education would increase students' knowledge on these aspects. 
The small change in attitudes on the OP from moderately neutral to slightly positive in this study is consistent with other research $^{[4,6,7,12,15,30]}$. These results suggested that nurses with a higher level of education acquire more positive attitudes towards older people ${ }^{[31]}$.

Remarkable is that only $3.7 \%$ of the fourth-year nursing students preferred to work with older people which is in line with other studies and indicated the growing need of motivated nurses to provide care for older people ${ }^{[4,5,10]}$. Fitzgerald et al. found that knowledge of older people was not associated with career intentions to care for older adults, but when interest in geriatrics increased, attitudes became more positive ${ }^{[28]}$. Additionally, $54.3 \%$ of the fourth-year students (54.3\%) indicated that they would not work with older people, which is striking because most students have a great interest in working in a hospital and it is known that the number of hospital admissions for Dutch people aged 65 years and older has increased in the past 20 years dramatically ${ }^{[3]}$. This indicates that current nursing students seem to be unaware of the phenomenon of changing demographics.

\section{Conclusion}

In conclusion, the findings of this study suggest that Dutch nursing students must be better prepared to work with predominantly older people. Results of this study do not provide information regarding the underlying causes influencing nursing students' attitudes toward older people. Although multiple studies have been conducted in this area, no single factor is dominant ${ }^{[9,10,14]}$. More research is needed to investigate these factors, including studies with a qualitative research design. Understanding nursing students' personal view concerning stereotypes, ageism and attitudes toward aging is the first step to change negative attitudes during their education.

It is important that all Dutch educators in nursing are aware of this lack of interest of nursing students in working with older people and focus on this area how this interest and attitudes can be improved. Working experience and increasing nursing students' contact with older people are essential elements to reach this goal ${ }^{[28,32]}$.

Future research is needed to investigate if a revised version of the curricula leads to an improvement on nursing students' knowledge of and attitudes toward older people. Inspirational educators and teachers are urgently needed to improve nursing students' attitudes and perception about aging and foster their interest in working with older people ${ }^{[14]}$. Given the international nature of the problem, collaboration within the international context of nursing educators might add to a solution. This strategy of improving nursing students' attitudes might enhance the quality of care for older people.

\section{Competing interests}

The authors declare that they have no competing interests.

\section{Acknowledgement}

We would like to thank all nursing students who participate in this study and the Hogeschool Utrecht (HU), University of Applied Sciences, who gave permission the conduct this study.

\section{References}

[1] Kinsella KG, Wan H, United States. Bureau of the Census. An aging world: 2008. : US Dept. of Commerce, Economics and Statistics Administration, US Census Bureau. 2008.

[2] Holroyd A, Dahlke S, Fehr C, Jung P, Hunter A. Attitudes toward aging: implications for a caring profession. J Nurs Educ. 2009; 48(7): 374. PMid:19634262 http://dx.doi.org/10.3928/01484834-20090615-04

[3] Statistics Netherlands. Hospital admissions [Internet]. 2011. Available from: http://www.cbs.nl/nl-NL/menu/themas/gezondheid-welzijn/cijfers/extra/2010-ziekenhuisopname.htm. Accessed May 16 th, 2011.

[4] Hweidi IM, Al-Obeisat SM. Jordanian nursing students' attitudes toward the elderly. Nurse Educ Today. 2006; 26(1): 23-30. PMid:16115699 http://dx.doi.org/10.1016/j.nedt.2005.06.003 
[5] Henderson J, Xiao L, Siegloff L, Kelton M, Paterson J. 'Older people have lived their lives': First year nursing students' attitudes towards older people. Contemporary Nurse. 2008; 30(1): 32-45. http://dx.doi.org/10.5172/conu.673.30.1.32

[6] Lambrinou E, Sourtzi P, Kalokerinou A, Lemonidou C. Attitudes and knowledge of the Greek nursing students towards older people. Nurse Educ Today. 2009; 29(6): 617-622. PMid:19243864 http://dx.doi.org/10.1016/j.nedt.2009.01.011

[7] Usta YY, Demir Y. Nursing students' attitudes toward ageism in Turkey. Arch GerontolGeriatr. 2011.

[8] Beullens J M, T. The attitude towards the elderly by nursing students. Verpleegkunde. 2000; 15(2): 74-80.

[9] Celik SS, Kapucu S, Tuna Z, Akkus Y. Views and attitudes of nursing students towards ageing and older patients. Australian Journal of Advanced Nursing. 2010; 27(4): 24.

[10] Shen J, Xiao LD. Factors affecting nursing students' intention to work with older people in China. Nurse Educ Today. 2011.

[11] Celik SS, Kapucu S, Tuna Z, Akkus Y. Views and attitudes of nursing students towards ageing and older patients. Australian Journal of Advanced Nursing. 2010; 27(4): 24.

[12] Lee YS. Measures of student attitudes on aging. Educational Gerontology. 2009; 35(2): 121-134. http://dx.doi.org/10.1080/03601270802523577

[13] McLafferty E. A comparison of nurse teachers' and student nurses' attitudes toward hospitalised older adults. Nurse Educ Today. 2005; 25(6): 472-479. PMid:15993516 http://dx.doi.org/10.1016/j.nedt.2005.04.007

[14] Cozort RW. Student nurses' attitudes regarding older adults: Strategies for fostering improvement through academia. Teaching and Learning in Nursing. 2008; 3(1): 21-25. http://dx.doi.org/10.1016/j.teln.2007.07.013

[15] Lu WH, Hoffman KG, Hosokawa MC, Gray MP, Zweig SC. First Year Medical Students. Educational Gerontology. $2010 ; 36(8): 15$. http://dx.doi.org/10.1080/03601270903534630

[16] Soderhamn O, Gustavsson SM, Lindencrona C. Reliability and validity of a Swedish version of Kogan's Old People Scale. Scand J Caring Sci. 2000; 14(4): 211-215. http://dx.doi.org/10.1080/028393100300006799

[17] Fishbein M, Ajzen I. Belief, attitude, intention, and behavior: An introduction to theory and research. 1975.

[18] Cowan DT, Fitzpatrick JM, Roberts JD, While AE. Measuring the knowledge and attitudes of health care staff toward older people: Sensitivity of measurement instruments. Educational Gerontology. 2004; 30(3): 237-254. http://dx.doi.org/10.1080/03601270490273169

[19] Palmore E. The facts on aging quiz: A review of findings. Gerontologist. 1980; 20(6): 669. PMid:7203089 http://dx.doi.org/10.1093/geront/20.6.669

[20] Rosencranz HA, McNevin TE. A factor analysis of attitudes toward the aged. Gerontologist. 1969.

[21] Kogan N. Attitudes toward old people: The development of a scale and an examination of correlates. The Journal of Abnormal and Social Psychology. 1961; 62(1): 44. http://dx.doi.org/10.1037/h0048053

[22] Pennington HR, Pachana NA, Coyle SL. Use of the facts on aging quiz in New Zealand: Validation of questions, performance of a student sample, and effects of a don't know option. Educational Gerontology. 2001; 27(5): 409-416.

[23] McCracken A, Fitzwater E, Lockwood M, Bjork T. COMPARISON OF NURSING STUDENTS'ATTITUDES TOWARD THE ELDERLY IN NORWAY AND THE UNITED STATES. Educational Gerontology: An International Quarterly. 1995; 21(2): 167-180. http://dx.doi.org/10.1080/0360127950210205

[24] CBS Statline. Health, lifestyle and care consumption [Internet]. 2010. Available from: http://statline.cbs.nl/StatWeb/publication/?DM=SLNL\&PA=03799\&D1=20,28-36,106,277\&D2=2,13-17,36-44\&D3=0\&D4=a\&VW=T. Accessed May 16th, 2011.

[25] CBS. Health and care statistics [Internet]. 2009. Available from: http://www.cbs.nl/nl-NL/menu/themas/gezondheid-welzijn/publicaties/publicaties/archief/2009/2009-c156-pub.htm.

[26] Harris DK, Changas PS, Palmore EB. Palmore's first facts on aging quiz in a multiple-choice format. Educational Gerontology: An International Quarterly.1996; 22(6): 575-589. http://dx.doi.org/10.1080/0360127960220605

[27] Polizzi KG, Millikin RJ. Attitudes toward the elderly: Identifying problematic usage of ageist and overextended terminology in research instructions. Educational Gerontology. 2002; 28(5): 367-377. http://dx.doi.org/10.1080/03601270290081344

[28] Fitzgerald JT, Wray LA, Halter JB, Williams BC, Supiano MA. Relating medical students' knowledge, attitudes, and experience to an interest in geriatric medicine. Gerontologist. 2003; 43(6): 849. PMid:14704384 http://dx.doi.org/10.1093/geront/43.6.849

[29] Kishimoto M, Nagoshi M, Williams S, Masaki KH, Blanchette PL. Knowledge and attitudes about geriatrics of medical students, internal medicine residents, and geriatric medicine fellows. J Am GeriatrSoc. 2005; 53(1): 99-102. PMid:15667384 http://dx.doi.org/10.1111/j.1532-5415.2005.53018.x

[30] Lambrinou E, Sourtzi P, Kalokerinou A, Lemonidou C. Reliability and validity of the Greek version of Kogan's Old People Scale. J ClinNurs. 2005; 14(10): 1241-1247.

[31] McKinlay A, Cowan S. Student nurses’ attitudes towards working with older patients. J Adv Nurs. 2003; 43(3): 298-309. PMid:12859789 http://dx.doi.org/10.1046/j.1365-2648.2003.02713.x

[32] Ferrario CG, Freeman FJ, Nellett G, Scheel J. Changing Nursing Students' Attitudes About Aging: An Argument For The Successful Aging Paradigm. 2008. 